\title{
ACTITUDES RELIGIOSAS Y PROVINCIANISMO. LITERATURA ALICANTINA EN EL SEXENIO DEMOCRÁTICO
}

POR

\author{
Alicia Mira ABAD \\ Departamento de Humanidades Contemporáneas \\ Universidad de Alicante
}

\section{RESUMEN}

Revisión de la literatura alicantina del Sexenio, estableciendo las propuestas de renovación y regeneracionismo de la Institución eclesiástica, centrándose en los artículos de prensa de todo tipo que se publican en esos ẫos.

\begin{abstract}
Review of the literature written in Alicante during the Sexenio, establishing the renovation proposals and "regeneracionismo" of the ecclesiastic Institution, especially in the press articles that are published in those years.
\end{abstract}

El Sexenio Democrático constituye un corto período de tiempo, aunque especialmente intenso en propuestas para acometer las transformaciones necesarias en el modelo de convivencia social imperante. Como señala Jutglar fue la «etapa más decidida y de mayor empuje, si cabe, de la acción de múltiples núcleos sociales burgueses hispanos» ${ }^{\mathrm{t}}$. La religión, por ser uno de los funda-

1 A. JutGlaR, De la Revolución de Septiembre a la Restauración, Planeta, Barcelona, 1976, p. 8.

Actas del I Congreso de Historia de la Iglesia y el Mundo Hispánico Hispania Sacra, $52(2000)$ 
mentos de ese modelo, pasaba a convertirse en el punto de mira principal de las propuestas de modernización trazadas por los revolucionarios. La Iglesia encarnaba el viejo orden y por tanto debia regenerarse.

La prensa del periodo refleja perfectamente este debate. Los revolucionarios alicantinos, por encima de enconadas discusiones y en ocasiones ataques furibundos al clero e incluso a la Iglesia-institución, no transgredieron en ningún momento la línea que delimita la religión y que les llevaría al ateísmo. Así pues se observa una tendencia general hacía una vía intermedia en la que el catolicismo y las libertades surgidas de la revolución pudieran convivir. Desde esta perspectiva las implicaciones temporales de la Iglesia debían desaparecer, circunscribiéndose al plano de la privacidad. En general, se observa una desinhibición a la hora de considerar que la supuesta esencialidad y el monolitismo católico español encubrían una variedad de matices y tendencias. Incluso dentro de la esfera del catolicismo se contemplan distintas posibilidades en torno al papel que debía ocupar la Iglesia en el nuevo orden social.

Todos estos elementos nos permiten hablar de la viabilidad de un proceso de secularización, que a pesar de sus peculiaridades experimentó una evolución en el período objeto de estudio, no solo desde el punto de vista institucional sino también en el actitudinal ${ }^{2}$. Este proceso dejó su impronta en la prensa. Sin embargo no es éste el único campo donde puede observarse. Aunque sin el mismo dinamismo y la claridad que caracteriza a las fuentes periodisticas, las literarias también pueden ofrecernos una visión sobre la cuestión religiosa en el Sexenio. Esto es precisamente lo que intentaremos analizar en los siguientes apartados.

\section{LA LITERATURA COMO FUENTE HISTÓRICA Y SU POTENCIAL PARA MOSTRAR LA REALIDAD SOCIAL. LITERATURA Y SUBLITERATURA}

Para poder acercarnos a la «historia total», el historiador debería considerar la psicología de las gentes que protagonizan un determinado momento histórico y que actúan como entes pasivos o activos de la historia. Las fuentes literarias son de gran valor en este sentido. Su interés estriba «en la información que proporcionan sobre valores, ideas y sentimientos». Sin embargo su utilización

\footnotetext{
${ }^{2}$ En el caso que nos ocupa el concepto de Secularización actitudinal se refiere a las vivencias y comportamientos de la sociedad ante los cambios suscitados por la revolución, en tomo a la cuestión religiosa. Se circunscribe a todas aquellas manifestaciones en las que pueden detectarse signos de desacralización, irreligiosidad o pervivencia de lo sacro en la militancia anticatólica. Vid. M. RevUeLTA GONZALEZ, «El proceso de secularización en Espafia y las reacciones eclesiásticas», en ÁLVAREZ LÁzARO (eds.), Librepensamiento y secularización en la Europa Contemporánea, UPCO, Madrid, 1996, pp. 321-372.
}

Actas del I Congreso de Historia de la Iglesia y el Mundo Hispánico Hispania Sacra, 52 (2000) 
requiere que el historiador tenga en cuenta varios aspectos. El primero se centra en la forma en que «ideas, valores y sentimientos de un texto literario responden al mundo de los personajes o al del autons. Hasta que punto esas idea, valores y sentimientos «son particulares de éste, propios de su ambiente social o compartidos por toda la cultura de su época». También es necesario tener presente que «la literatura no es solo el reflejo pasivo de una cultura, es también un agente creador de valores y mitos) ${ }^{3}$. A pesar de que nos encontramos ante una fuente histórica de gran valor, ésta es tan solo una aportación parcial a un panorama complejo cuyo acceso debe realizarse a través de otras fuentes y materiales contrastados.

La viabilidad de un análisis histórico con literatura como fuente no debería incidir en el estilo sino en su capacidad para acercarnos a la mentalidad de una época. Como señala Vovelle la literatura «vehicula las imágenes, los clichés, los recuerdos y las herencias» instituyéndose en registro de «los estremecimientos de la sociedad colectiva» ${ }^{4}$. Al "mostrar la sustancia de las ideas que defendieron y elaboraron" los autores, se está recreando de alguna forma el medio en que vivieron y los valores y actitudes de una parte significativa de la sociedad a la que pertenecían ${ }^{5}$. Por ello, a pesar de la obligada parcialidad, la obra literaria cobra valor de «documento histórico que ofrece testimonios directos sobre la realidad de las sociedades implicadas $\aleph^{6}$.

Sin embargo muchas de las obras a las que nos enfrentamos no se acercan precisamente a la altura que poseen las producciones de autores como Galdós, Pereda, Valera, Alarcón o Pardo Bazán, adscritos a la llamada Generación del $68^{7}$. No estamos sefialando este aspecto desde la óptica de la crítica literaria sino desde las posibilidades de la obra como fuente de información para el historiador. Tanto la narrativa, poesía como las escasas obras de teatro estudiadas traducen aspectos aparentemente poco relevantes de la sociedad en la que se ubicaron y la mayoría responden a esquemas preconcebidos y a fórmulas literarias heredadas del romanticismo que perduraron sin apenas variaciones hasta el siglo $\mathrm{XX}^{8}$. Pero a pesar de su escasa altura literaria, al desbrozar los textos de

\footnotetext{
3 J. AvILÉs FArRÉ, «Fuentes literarias e Historia social», en Studia Historica, Vol VI-VII, Universidad de Salamanca, Salamanca, 1990, pp. 67-78.

${ }^{4}$ M. VolelLe, Ideologias y Mentalidades, Ariel, Barcelona, 1985, p. 49.

s I. M. ZAVALA, Ideologia y politica en la novela española del siglo XIX, Anaya, Madrid, 1971, p. 12.

${ }^{6}$ E. Cros, Literatura, ideología y sociedad, Gredos, Madrid, 1986, p. 14.

7 Sobre la Genración del 68 vid. J. A. Ferreras, «La prosa en el siglo XIX», en J. M." DíEZ BorQUE, Historia de la Literatura Española, (III) Siglos XVIII-XIX, Taurus, Madrid, 1982, pp. 405-427.

\&. Rfos CarratalÁ, «El naturalismo en un ámbito provinciano: Alicante, 1875-1900», en Y. LYsSORGES, Realismo y naturalismo en España en la Segunda mitad del siglo XIX, Antrhopos, Barcelona, 1988, pp. 169-179.
} 
las mismas se extraen gran cantidad de elementos relacionados con los usos y costumbres de dicha sociedad y por su puesto aquellos relacionados con actitudes religiosas. En su conjunto estas obras no son testimonio fiel y directo de las inquietudes de la época ni de la sociedad a la que supuestamente se dirigieron. Sin embargo, la propia intención con que fueron escritas puede estar indicándonos algunas de las numerosas contradicciones que marcaron los planteamientos religiosos de una sociedad que hasta el momento había sido considerada como esencialmente católica?.

Por su contenido la mayoría de las obras analizadas se insertan dentro de lo que algunos autores definen como subliteratura o paraliteratura. Andrés Amorós sef́ala el interés sociológico de este género que en ocasiones puede ir acompañado de un interés literario bastante considerable. La obra literaria refleja la sociedad, pero la «subliteratura puede hacerlo con mucha nitidez, ofreciéndonos la escala de valores de una sociedad o de sus grupos sociales; en definitiva, sirviendo a la historia de las mentalidades». La frontera entre ambos conceptos es ambigua y puede variar a lo largo del tiempo. Su delimitación se establece en función de la calidad. Sin embargo este elemento no debe condicionar la seriedad de un trabajo de investigación que «depende del rigor con que se realice, no de la materia estudiada ${ }^{10}{ }^{0}$. José-Carlos Mainer basa esta diferenciación en el tipo de receptividad del público al cual pueden ir dirigidas estas obras. Frente a la actitud expectativa del lector ante la literatura, encontramos, en el caso de la subliteratura, una «esperanza concreta de un cliché argumental o sentimental y, en definitiva, una cierta dictadura sobre la condición del producto que se le sirve. Y a ello sirve, naturalmente, una literariedad avulgarada y de receta) ${ }^{11}$. Esta predeterminación psicológica del lector ante la subliteratura es perfectamente explicable si se observan algunos de sus rasgos definitorios más notables. El primero sería la simplicidad argumental y psicológica de los personajes, favoreciendo que la mayor de estas producciones literarias se conviertan en un conjunto de tópicos socialmente admitidos y encadenados en una trama pseudoliteraria. El «dualismo moral sociopolítico» ${ }^{12}$, especialmente manifiesto

\footnotetext{
${ }^{9}$ Por ejemplo, la gran cantidad de poemas piadosos que aparecen en este momento no indican el clima religioso imperante sino que muy bien pueden constituir una una especie de revulsivo a la «novelística anticlericalm. Vid. J. A. Ríos Carratalá, Romónticos y Provincianos (La literatura en Alicante, 1839-1886), Universidad de Alicante, 1987, p. 22. 45.

10 A. AMorós, Subliteraturas, Ariel, Madrid, 1974, pp. 8 y 9. Vid. también M. VolelLe, op. cit., p.

I J. A. MAINER, Historia, literatura, sociedad, Espasa-Calpe, Madrid, 1988, p. 113. J. A. Rjos CARratalá, señala en estos autores la "voluntad creadora y estética es sustituida por una labor artesana que procura satisfacer las demandas de un lectorado que busca constantemente las mismas historias en idénticos moldes», en Románticos yProvincianos, p. 108.

12 V. GarCfa DE LA CONCHA, op. cit., p. 42.
}

Actas del I Congreso de Historia de la Iglesia y el Mundo Hispánico Hispania Sacra, 52 (2000) 
en la producción narrativa y teatral, es otro elemento caracterizador de estas producciones. Tanto situaciones, como personajes transcurren entre el bien y e mal. No existen a penas matices o medias tintas que compliquen las tramas. La temática por tanto queda constrenida a una serie de temas básicos, y los personajes actúan movidos por sentimientos primarios relacionados con la pobreza, la riqueza, el amor, la honra, etc. ${ }^{13}$. Este maniqueísmo se proyecta en las cuestiones religiosas de una forma clara: todos los comportamientos y actitudes que se apartan de la ortodoxia católica se encuentran ligados a los personajes más ruines. El sentimentalismo, que como señala Diez Borque es más bien «sentimentalina rastrera las más de las veces» ${ }^{14}$, es otro de los rasgos característicos de este tipo de producciones. El autor intenta exaltar nobles sentimientos, quizás con la «sana y bienintencionada misión» de incrustarlos en la mente del lector. Unos sentimientos religiosos «correctos» constituyen un componente esencial en dicha exaltación, siendo especialmente evidente en las mujeres.

El folletín es el protagonista indiscutible de la producción literaria del momento. Su estructura se encuentra sometida en la mayoria de los casos a las exigencias del mercado, por lo que la falta de atención a elementos históricos, geográficos o narrativos es patente. Su desarrollo no se circunscribe tan solo a la novela, ya que en este género también tienen cabida las «biografias noveladas, obras de historia novelizadas o collages de historia contemporánea y de ficción». En todas ellas puede distinguirse un denominador común: el estilo literario es prácticamente nuło, puesto que este tipo de obras estaban dirigidas por lo general a un público «poco letrado y solo familiarizado con el lenguaje oral». Assí la lengua se convierte en mero instrumento para «señalar e ilustrar la realidad de lo que ocurre» ${ }^{15}$.

\section{LA EFICACIA IDEOLÓGICA DE LOS ESCRITOS LITERARIOS EN LA SOCIEDAD}

El concepto de pueblo es difuso. La prensa y la literatura del momento reflejan una serie de valores y nuevas ideas cuya incidencia popular es difícil de calibrar. Como veremos posteriormente, la mayor parte de los autores analizados hace hincapié en la ignorancia, como lacra social que convierte al pueblo en un títere a merced de los vaivenes revolucionarios, sin ninguna capacidad para

${ }^{13}$ Vid. sobre la temática folletinesca, M. ${ }^{2}$ C. LecuYer y M. VILLAPIEDRa, "Génesis y desarrollo del folletin en la prensa espanfolay, p. 36, en B. MAGNIEN, Hacia una literatura del pueblo: Del folletín a la novela, Anthropos, Barcelona, 1995.

${ }_{14}$ J. M. DiEz BORQUE, Literatura y cultura de masas. Estudio de la novela subliteraria, Al-Borak, Madrid, 1972, p. 39.

15 V. GARCtA DE LA CONCHA, op. cit., pp. 42 y 677.

Actas del I Congreso de Historia de la Iglesia y el Mundo Hispánico

Hispania Sacra, 52 (2000) 
emitir o por lo menos filtrar adecuadamente las nuevas ideas de progreso que acompañan a la revolución. Por el contrario en determinados momentos se alude al mismo como un ente idealizado al que se atribuye una sabiduría y capacidad de decisión innatas y sobre todo se considera principal guardián de la tradición. Así el propio Galdós afirma que «el pueblo posee las verdades grandes y en bloque, y a él acude la civilización conforme se le van gastando las menudas de que vive» ${ }^{16}$. Pero lo cierto es que la mayor parte del pueblo al que alude Galdós no sabía leer ni escribir, por lo que es dificil calibrar como y de qué se nutría la sabiduria popular. Juan Avilés Farré señala que «la literatura no es solo el reflejo pasivo de una cultura» sino que también actúa como «agente creador de valores y mitos». Desde este punto de vista, habrá que estudiar el impacto social de la obra literaria y su incidencia en la mentalidad colectiva ${ }^{17}$.

Si se considera que la creación literaria además de ser espejo de valores y costumbres sociales puede influir sobre ellos será necesario analizar la cantidad y calidad del público consumidor. En este sentido es de todos conocido el escaso índice de alfabetización en el periodo objeto de estudio. En general el acceso directo de los españoles a la lectura fue sumamente restringido en el siglo XIX, con un porcentaje de analfabetos que puede estimarse hacia 1860 en el $80 \%$ de la población ${ }^{18}$. La progresión en la alfabetización crece a un ritmo lento y desigual por lo que el índice de alfabetizados es muy bajo, un dato que resulta especialmente evidente si comparamos la situación espafiola con la de otros países europeos. En España los estudios realizados al respecto señalan a la Comunidad Valenciana y en particular a Alicante como zonas que registran los indices más bajos en contraposición a otras provincias. Sin embargo hay que considerar el desfase existente entre el número de alfabetizados en las ciudades y en el campo. Así, Alicante presenta en el af́o 1860 un 22, 79\% de población alfabetizada en la capital frente a un $9,48 \%$ en el resto de la provincia ${ }^{19}$. En este panorama tan desalentador la mujer representa a un sector de la población con uno de los porcentajes más bajos de alfabetización (tan solo el $22,90 \%$ del total de personas alfabetizadas en 1860) y sin embargo es ella sobre quien la llamada subliteratura tiene una especial acogida ${ }^{20}$, por lo que cabría suponer entonces que la incidencia social de gran parte de las obras analizadas fue escasa.

\footnotetext{
${ }^{16}$ Citado en C. Blanco Agutnaga, J. Rodriguez Púrtolas, e I. M. Zavala, Historia social de la Literatura española, Vol. II, Castalia, Madrid, 1979, p. 163.

17 J. Avilés FarRé, op, cit., p. 74.

18 Ibidem, pp. xix y $\mathbf{x x}$.

19 J. F. BorkelL, Libros, Prensa y Lectura en la España del siglo XZX, Pirámide, Madrid, 1993, pp. 304-339.

20 J. F. Botrell, Ibidem, p. 310. García DE LA CONCHA, señala que «la mujer aparece desde el comienzo de siglo como lectora de novelas y especialmente inclinada a orientar sus sentimientos y u
}

Actas del 1 Congreso de Historia de la Iglesia y el Mundo Hispánico

Hispania Sacra, 52 (2000) 
El fraccionamiento de la producción y la adquisición con el sistema por entregas, como elementos que influyeron en una mayor popularización de la lectura son otras variables a tener en cuenta en una cuestión cuyo desarrollo exhaustivo no cabe en el marco de este trabajo. Así pues, más que considerar a estas obras como vehículo doctrinario se trataría de observarlas como reflejo de mentalidades, aunque la intencionalidad con que algunas de ellas fueron escritas fue el adoctrinamiento popular.

\section{PANorama literario alicaNTINo y MENTALIDAD RELIGiosa}

El presente estudio no pretende mostrar la situación literaria de Alicante en un marco cronológico muy concreto, ni mucho menos ofrecer una visión crítica de las obras analizadas. Nos serviremos de ellas para intentar extractar en la medida de lo posible la posición de sus autores frente a la cuestión religiosa así como los indicios de religiosidad popular. La escasa calidad de la mayor parte de las obras analizadas no impide que podamos hacernos eco de mentalidades, ideologías, usos y costumbres de los alicantinos durante el Sexenio

Hemos seguido para realizar nuestro estudio a Manuel Rico García ${ }^{21}$ y a Juan Antonio Ríos. Como seffala este último «la exhaustividad es una quimera» ya que muchas de las obras reseffadas por Rico García en su Ensayo Biográfico Bibliográfico se han perdido. Por otro lado, parte de la producción literaria que sustenta el presente estudio fue editada en Madrid, aunque su inclusión en este trabajo queda justificada por el hecho de que fuera escrita por alicantinos. Hay que tener en cuenta que la literatura alicantina no alcanzó una especificidad propia y una entidad suficiente hasta el siglo XX. Según Ríos «en el período previo no surgen autores con la suficiente personalidad creadora como para captar su entorno con una sensibilidad peculiar» y sobre todo para «incorporarlo creativamente a su obra ${ }^{22}$. Vicente Ramos ${ }^{23}$, en cambio, insiste en dicha especificidad y la fundamenta en unos rasgos «concretos y comunes» en todos los autores -liberalismo, generosidad, democracia, individualismo y amor a la Naturaleza- que sin embargo no se encuentran reflejados en unas obras caracterizadas por su

conducta imitando modelos literarios, con gran peligro y muy frecuentemente quebranto de su honestidads, en op. cit., p. xxx. J. A. Rtos CARRATALA, corrobora la existencia de un «lectorado mayoritariamente femenino" que sólo udeseaba lacrimosas y virtuosas historias que se repetían a si mismas y se consumian independientemente de quienes fueran sus autoressen Románticos y provincianos, p. 108.

21 M. Rico GARcí, Ensayo Biográfico Bibliográfico de escritores de Alicante y su provincia, Instituto Juan Gil Albert, Alicante, 1987.

22 J. A. Ríos Carratalá, Románticos y provincianos..., p. 15.

23 V. RAmos, Literatura alicantina (1839-1939), Alfaguara, Madrid, 1966. 
convencionalismo ${ }^{24}$. Este es un aspecto que podemos corroborar por nuestra parte y sobre el que volveremos más adelante. Incidir únicamente en que los convencionalismos y la moderación característicos en la mayor parte de las obras analizadas -que en ocasiones rozan la mojigatería-contrastan frente a la expresividad arrolladora y sin tapujos de algunos periódicos del momento.

Esta moderación podría explicarse a través de dos elementos: el status del escritor y el miedo a la revolución. En el primer caso hay que hacer hincapié, como peculiaridad distintiva del siglo XIX, en «la conversión generalizada de la obra literaria en un producto sujeto a las leyes de un mercado». El escritor «indefenso ante las oscilaciones de esa demanda» se ve obligado a subordinar su libertad creativay ${ }^{25}$. Para el caso concreto de Alicante, Juan Antonio Ríos señala que sólo se puede afirmar parcialmente el tradicionalismo de sus autores. Más que una cuestión ideológica se trataría de la función que se otorga a un autor en la sociedad provinciana de aquel momento. «Este podía expresarse como individuo liberal o conservador, pero dentro de los límites del decoro de dicha función que en lo literario suponía un rechazo de todo el materialismo, positivismo, realismo, escepticismo y naturalismo». El verdadero objetivo del autor debía ser embellecer la realidad y uen el caso de ejercer la crítica, hacerlo elegantemente generalizando y sin descender a lo real o inmediato ${ }^{26}$. En cuanto al segundo aspecto señalar, como denominador común en los autores alicantinos integrantes de una burguesía acomodada, el miedo a que la revolución se extendiese de forma incontrolada a las masas. Rosa Ana Gutiérrez afirma que la progresiva radicalización política y el «peligro del socialismo-federalismo, independientemente de que fuera o no real, sirvió de elemento de conjunción ideológica» a un sector de la burguesía. Alguno de los autores analizados pese a considerarse republicano se alineó con las posturas más moderadas que abogaban por sacrificar parte de las libertades conseguidas con la revolución para «reprimir los avances políticos del proletariado ${ }^{27}$. La religión en este sentido era un eficaz baluarte defensivo frente al desorden social. Así pues, el conservadurismo político de nuestros autores se hará extensivo al religioso. En ninguna de sus obras encontramos indicios de crítica que menoscabe la trascendencia e importancia de la vivencia religiosa colectiva o individualmente. Se muestran sumamente cautos al recrear aspectos relacionados con la religión o con la Igle-

24 J. A. Ríos Carratala, Románticos y Provincianos..., p. 16.

25 V. GARCiA DE LA CONCHA, Historia de la Literatura española, p. xxiv y xxv.

${ }^{26}$ J. A. Ríos CarratalA, «El naturalismo en el ámbito provinciano", en op. cit., p. 171.

${ }^{27}$ R. A. GUTtÉRREZ LLORET, Republicanos y liberales. La Revolución de 1868 y la $1^{\circ}$ República en Alicante, Instituto Juan Gil-Albert, Alicante, 1985, pp. 22-160. «E1 terror a la revolución social» es también una constante en escritores de primera fila como Valera o Alarcón, en F. PÉrez GUTIÉRREZ, El problema religioso en la Generación de 1868. "La Leyenda de Dios», Taurus, Madrid, 1975, pp. 82 y 110.

Actas del I Congreso de Historia de la Iglesia y el Mundo Hispánico Hispania Sacra, 52 (2000) 
sia-Institución e incluso algunas de estas obras podrían considerarse como verdaderos panegíricos religiosos ${ }^{28}$.

Como señalábamos anteriormente no va ser ésta una caracterización literaria de diversos autores centrada en su actitud frente a la religión. La estructura de la presente investigación se ordena a través de diversos elementos sobre los que gira la cuestión religiosa en el Sexenio, es decir, indicadores o indicios de secularización social en un momento en que surgen planteamientos modernizadores en el plano institucional. Así pues, las manifestaciones de religiosidad popular, el anticlericalismo, la visión de la Iglesia y el clero, los valores y moral vigente, la mujer, las heterodoxias foráneas e institucionales frente a la ortodoxia del pueblo español, el até́smo o la ignorancia del pueblo y el orden social desde el punto de vista religioso serán las cuestiones que centren nuestro interés, en el marco de un panorama literario cuyos autores insisten, en muchas de sus obras, en la veracidad de los hechos que relatan o por lo menos en su imparcialidad a la hora de relatarlos ${ }^{29}$.

\section{III.1. Manifestaciones de religiosidad popular}

Las manifestaciones y ritos religiosos constituyen uno de los canales de ideologización más efectivos que la Iglesia ha utilizado tradicionalmente para mantener su control sobre la sociedad. Son para muchos indicios que permiten calibrar la religiosidad del pueblo. Aunque la autenticidad religiosa con la que la gente concurría a este tipo de actos es más que discutible, lo que es innegable es su raigambre social y el poder de atracción que aún hoy pervive. Alguno de los autores analizados en el presente trabajo ensalzaron en sus obras este tipo de

\footnotetext{
28 A pesar de que el tema religioso aparezca representado en las obras analizadas, en contadas ocasiones existen indicios de debate o preocupación social sobre esta cuestión en unos autores que parten de la supuesta esencialidad del catolicismo espafiol. Soledad MiRanda, en Religión y Clero en La gran novela española del siglo XIX, Pegaso, Madrid, 1982, p. 3 seffala que «lo más característico del hecho español será no solo el que los principales autores empufien su pluma en el tratamiento de la problemática religiosa, sino el que todos los nombres de segunda fila aparezcan cohesionados por idéntica temáticas, un elemento que sin embargo no cohesiona a los autores alicantinos de este periodo. La misma autora entra en cierta contradicción al preguntarse "cpor qué cuando lo eclesial prima en el panorama nacional los novelistas lo postergan?", atribuyéndolo a un comportaniento oportunista o quizás a un deseo de no avivar la discordia sobre una cuestión tan espinosa. Vid. p. 256.

${ }^{29}$ Algunos de los ejemplos más significativos de ello los constituyen Juan Vila y Blanco, Llofriu y Sagrera o Juan Rico y Anat. En el caso de Eleuterio LLofrru este deseo de parecer imparcial le lleva en ocasiones a serias contradicciones: «Como somos imparciales debemos consignar una circunstancia que viene en apoyo de nuestras opiniones en cuanto a la honradez de nuestro pueblo" en: E. LLOFRiU Y SaGrERA y R. ORTEGA Frías, Insurrección federal en 1873. Sus causas y consecuencias. Sus misterios politicos y sociales. Sus hombres. Sus dramas y horrores con todos los detalles, Madrid, 1873, p. 442 T. I.
} 
ritos, haciendo hincapié en la calidad y la cantidad de asistentes, lo cual es muy lógico desde una posición predominantemente conservadora, en la que la iglesia seguía siendo un útil instrumento de tranquilidad social frente a los tempestuosos tiempos revolucionarios. El lector capta en la mayoría de las obras en las que se alude a estas cuestiones una clara afinidad del autor por los ritos religiosos, que en el caso de Juan Vila y Blanco y La ermita del Santísimo Sacramento alcanza un nivel de propaganda.

Esta obra pretende ser un bálsamo para los creyentes en unos días en los que «la impiedad y el ateísmo» se expanden por doquier. En ella narra el hallazgo milagroso de un viril robado en la localidad de Tibi. Este «horrible crimen» desencadenó» tras su milagrosa resolución, una reacción por parte del católico pueblo, «ultrajado y herido tan torpemente en el corazón» que se materializó en la construcción de una ermita en el lugar del hallazgo. Los «impíos e incrédulos» pueden pensar que estos sucesos son meras «disposiciones marcadas en el orden regular de la naturaleza, que nada tienen de maravilloso, sino en las cabezas, como dicen, fanatizadas por la superstición en la opinión del vulgo seducido más novelero. Pero es cierto ${ }^{30}$. Tras relatar extensamente el suceso. Vila y Blanco se dedica a describir las numerosas procesiones organizadas para celebrar el milagro cuya nota común es la intensa piedad y el número apabullante de participantes ${ }^{31}$. Estas «escenas tan grandiosas capaces de ablandar los corazones más duros, los empedernidos corazones de los impíos y de los libertinos», no son para Vila y Blanco susceptibles de convertirse en fanatismo. Es más, el autor piensa que el «sentimiento religioso, aún el más profundamente herido por circunstancias dolorosas y apremiantes, dista mucho de ser fanático y dista muchísimo más de ser cruel. La religión principia siempre por educar en la virtud» $\rangle^{32}$.

También Eleuterio Llofriu hace hincapié en la creencias religiosas del pueblo que en todo momento da pruebas de sincera piedad. Al igual que en el caso anterior un templo surgido para conmemorar un hecho milagroso se convierte en objeto de veneración popular. Esta vez es Granada y la Virgen de las Angus-

30 J. Vila y Blanco, La Ermita del Santisimo Sacramento y de nuestra Señora del Rosario en la Pedrera, Alicante, José Marcili Oliver, 1873, pp. VI y 68. En otros pasajes de la obra se insiste en la veracidad de los milagros. Vila y Blanco trata de establecer una correlación entre la ciencia y estos acontecimientos que ilustra con un articulo aparecido en $L$ 'Année scientifique et industrielle, referido a una lluvia de estrellas en la noche en que se celebraba el milagro en la Pedrera. El autor lo califica como un «espectáculo astronómico, que no esperaban en tal noche ni los iniciados en la ciencia», p. 166.

31 Ibidem, p. $36 . \mathrm{El}$ autor reitera en varias ocasiones la cantidad de asistentes a otras procesiones, pp. 99,204 y 205.

32 Ibidem, pp. 40 y 54.

Actas del I Congreso de Historia de la Iglesia y el Mundo Hispánico

Hispania Sacra, 52 (2000) 
tias ante cuya imagen ni »los más descreídos se atreverían a cometer una irreverencia». Los granadinos nacen ya con la devoción a esta imagen «inculcada en el alma». De tal forma que «en todas las tribulaciones, en todos los apuros, en todos esos momentos solemnes y terribles de la vida, acuden los granadinos al santuario de la Virgen para pedirle consuelo». El autor de Insurrección Federal resalta especialmente la afluencia de fieles al seffalar que «a ninguna hora faltan devotos $\aleph^{33}$. Asimismo don Eleuterio caracteriza en La mujer de Alicante la religiosidad de las gentes que integran los diversos pueblos de la provincia. Al «carácter festivo» se une el sentimiento religioso, de forma que se celebra «cualquier solemnidad religiosa, especialmente las del Santo Patrón de la localidad», siendo la mujer «la que ha perpetuado esas tradiciones populares» y la que «con religioso respeto" lleva a sus hijos a que vean el altar hasta el punto de que «ilos nifios enloquecen!». En Elche «el nombre solo de la Virgen «basta «para enternecer el corazón más duro. Y ha llegado a tal extremo la veneración, el respeto, el amor ferviente, que muchas mujeres ricas han dejado a la Virgen bienes cuantiosos (...). Es tan viva la fe en el corazón de la ilicitana, y la ha infundido de tal modo en el alma de sus hijos, que todo lo bueno que sucede en Elche se atribuye a los milagros de la Virgen». Como todo evento religioso existe un ritual. A pesar de que la mujer no desempeña papel alguno en el «misteri» a causa «de las costumbres severas de los tiempos» en los que se instituyeron estas ceremonias, siempre hay rituales paralelos en los que poder mostrar públicamente el sentimiento religioso:

"La hacendosa ilicitana prepara su casa para los huéspedes que en aquellos días no son pocos; arregla sus mejores trajes para lucirlos en los paseos y en las calles, dispónese a cumplir la promesa de salir en la procesión con el cabello suelto, acaso con los pies desnudos o recorriendo la larga carrera de rodillas dos veces» ${ }^{34}$

La Virgen o el patrón del pueblo no tenían la exclusiva de las manifestaciones religiosas. También la visita de los reyes Amadeo I y $\mathrm{M}^{\mathrm{a}}$. Victoria a Alicante propició la organización de este tipo de actos. José Pastor de la Roca y Blas de Loma y Corradi en sendas obras sobre el viaje de los monarcas a la capital alicantina narran como discurrieron. En primer lugar se acordó «cantar un solemne Te-Deum en la Colegiata de San Nicolás, también se adoptaron medidas de caridad oficial como «dar comida extraordinaria a los acogidos en los establecimientos de beneficencia y a la presos de la cárcel». Además se distribuyó entre «las nodrizas de expósitos de toda la provincia un donativo equiva-

33 E. LlOFruU Y SAGRERA, Insurtección Federal, p. 279, T. II.

34 E. LlOFRIU Y SAGRERA, La mujer de Alicante, De Las mujenes españolas, portuguesas y Americanas, Madrid, Alicante, 1872-1876 pp. 42-50.

Actas del I Congreso de Historia de la Iglesia y el Mundo Hispánico Hispania Sacra, 52 (2000) 
lente a una mensualidad). Todas estos actos culminaron con una visita a la Santa Faz, cuya narración por parte de Pastor de la Roca pone de manifiesto la importancia de la costumbre en los ritos religiosos, uno de los elementos más criticados por quienes reivindicaban una depuración eclesiástica ${ }^{35}$.

Las desgracias también eran un motivo idóneo para reclamar la atención celestial. Nicasio Camilo Jover en Las fragatas insurrectas y el bombardeo de Alicante enumera las medidas religiosas de carácter extraordinario que se tomaron y la congregación clerical que tuvo lugar, señalando que «los templos de San Nicolás y de Santa María, se abrieron desde el amanecer (...) dispuestos a prestar auxilios espirituales a quien pudiese necesitarlos ${ }^{36}$.

\section{III.2. El anticlericalismo}

Las escasas referencias al anticlericalismo en los autores analizados constituyen un claro indicador de la mesura con que la cuestión religiosa atraviesa sus obras. No solo huyen de disquisiciones filosóficas en la línea de aquellos anticlericales que «tratan de conceptualizar su actitud», defendiendo «un tipo se sociedad basada en la racionalidad y en la explicación del hombre y del mundo con argumentos inmanentes, sin cifrar en lo divino y trascendente la última motivación $)^{37}$. Podemos observar incluso una clara actitud favorable al clero, a excepción de los jesuitas, que puede parecer un contrasentido si se analiza la prensa alicantina del momento, donde el anticlericalismo, especialmente en su vertiente crítica frente a los vicios clericales, aparece profusamente representado. Esto nos lleva a consignar, una vez más, el marcado carácter conservador de los autores alicantinos.

Eleuterio Llofriu constituye un claro ejemplo de ello al narrar desde su óptica particular el estallido revolucionario en Málaga. Además de hacer pública profesión de fe ofrece la imagen de unas monjas desamparadas obligadas por los revolucionarios a dejar el convento, "como si no tuviesen un perfecto derecho a reunirse y asociarse y a vivir como les conviene en el interior de su morada), y de un obispo, cuya virtud más destacable, según el autor, era el no haberse mezclado nunca en cuestiones políticas, algo poco habitual en el clero de la

35 J. PASTOR DE LA ROCA, Viaje a Alicante de SS. MM. Amadeo Iy M. ${ }^{a}$ de la Victoria, Imprenta de Juan J. Carratalá, Alicante, 1871, pp. 27-28. Cfr. B. DE Loma y Corradi, Entrada en España de la Reina $M^{\prime}$. Victoria, Alicante, Imprenta de José Gossart, 1871, quien asimismo se refiere a los rituales de costumbre, p. 31.

${ }^{36}$ N. C. Jover, Las fragatas insturrectas y el bombardeo de Alicanie, Alicante, 1873, p. 135.

37 E. La Parra López y M. SUÁrez CorTina (eds.), El anticlericalismo español contemporáneo Biblioteca Nueva, Madrid, 1998, p. 13.

Actas del I Congreso de Historia de la lglesia y el Mundo Hispánico

Hispania Sacra, 52 (2000) 
época. Este prelado que se ceñía a las obligaciones de su sagrado magisterio, era por tanto injustamente maltratado por los revolucionarios:

«Se atentó contra los derechos del anciano y venerable obispo, que a nadie había hecho mal, y que olvidándose de la política, se habia ocupado siempre en cumplir los deberes de su sagrado ministerio de paz y caridad. Invadieron su morada, diciéndole que aquel edificio pertenecía la pueblo soberano, y el anciano sacerdote tuvo también que salir de la población, si bien no lo hizo ocultamente ni como quien huye, sino con la serenidad del que tiene su conciencia tranquila. ¿Así entiende el pueblo malagueño la libertad?. Con tales extravios y exageraciones, no se consigue más que desacreditar las doctrinas liberales. ¿Es así como los partidarios de la república piensan engrosar sus filas? $\rangle^{38}$

También el anticlericalismo verbal se encuentra representado en los textos analizados. Las continuas referencias a Roque Barcia, calificado en su tiempo como «apóstol de las nuevas ideas» es una muestra de ello. Barcia, revolucionario que propugnaba la vuelta a una depuración eclesiástica para acabar con la corrupción clerical, incluido el papa ${ }^{39}$, es considerado por Eleuterio Llofriu como miembro de la «fracción intransigente» y principal instigador de la sublevación cantonal en Cartagena. A través de sus escritos y su periódico La Justicia Federal, que era «leído con avidez y comentado, encendiendo el espíritu hasta de los más pacíficos, este hombre, «enajenado según el entusiasmo con que se expresabas, daba «aliento a las turbas entre las cuales buscaba conservación de su popularidad». Llofriu, en contra de lo que es habitual en sus obras, lleva a cabo un fugaz perfil psicológico de este personaje poniendo de relieve las contradicciones existentes entre su vida privada y pública:

«Roque Barcia era un tipo especial. El estilo de sus obras políticas y literarias, tan original como su carácter. Decía que era incapaz de matar a una hormiga y sin embargo escribía artículos incendiarios (....). Su lógica estaba al alcance de las masas y para ellas escri-

\footnotetext{
38 E. Llofrdu Y SAGRERA, Instarección Federal, p. 227 T.I. En la p. 352 de la misma obra el autor vuelve a sefialar que «nada se ha respetado, y del furor de las masas populares no se han librado ni las pobres mujeres que han buscado tranquilidad y refugio en el retiro de su celdan. Cfr. la obra del autor valenciano coetáneo Francisco PALANCA y ROCA, iValencianos con honra!, Valencia, 1869-70, donde se narran «los acontecimientos ocurridos durante la terrible lucha sostenida en Valencia en Octubre de $1869 \%$. Uno de los pasajes de esta obra teatral ofrece un comentario escénico muy significativo en el que los republicanos desalojan a unas monjas del convento con sumo cuidado, intentando con ello hacer ver las buenas intenciones que guían a los voluntarios en las luchas revolucionarias: «Comentario escénico: Varios vecinos acuden en socorto de las monjas, que se van viendo pasar acompañadas de los voluntarios que les prodigan mil atenciones; los vecinos las hacen beber tazas de caldo. Se recomienda a los directores de escena que se cuiden mucho de este pasaje históricom, p. 24.

${ }^{39}$ Vid. Algunas de las obras más significativas en este sentido de R. BARCiA, Cartas a su Santidad Pio Nono, precedidas de una carta que desde el otro mundo envian a su Santidad los masones Monti y Togneti, Madrid, 1869, El Evangelio del pueblo, Madrid, 1868, o La Teoria del Infierno o La Ley de la vida, Madrid, 1868.
} 
bía (....). Lo más extraño en él era que en el interior del hogar admirábase al cariñoso padre de familia, amante de sus hijos, bondadoso y dispuesto a sacrificarse por ellos» ${ }^{40}$.

La crítica anticlerical solo surge en Eleuterio Llofriu relacionada con la Compañía de Jesús ${ }^{41}$. Todas las alusiones a los jesuitas que encontramos en Insurrección Federal están vinculadas con una misteriosa conspiración integrada por agentes extranjeros, carlistas, republicanos y socialistas que planean la destrucción del país. Aunque los intereses de todas estas facciones son claramente divergentes prevalece sobre todo la idea de confundir y dominar al incauto pueblo español para favorecer los respectivos intereses. Don Eleuterio a través de Pedro Lefranc, de quien «decíase que asistía a reuniones de jesuitas y que recibía sus inspiraciones» quiere mostrar la imagen de una orden religiosa que actúa en la sombra, al margen incluso de la propia Iglesia. El objetivo algo difuso, como todo en esta obra, de este «auxiliar eficacísimo de la Compañía de Jesús» era favorecer los planes de devastación para que después de ellos viniera una reacción formidable y vólviese la idea católica a predominar en toda su pureza». Con estas referencias el autor quiere hacer constar su talante liberal conservador y su rechazo al reaccionarismo y el fanatismo, que considera «hijos de la ceguedad y de la ignorancia ${ }^{42}$.

40 E. LlOFRIU Y SAGRERA, Insurrección Federal..., pp. 310, 595, 686, 788 y 1021. T. I. En las pp. 540-543, este autor introduce a Barcia en la trama de su narración al señalar que el pérfido agente secreto de la Internacional, Pedro Lefranc, envía una serie de escritos al periódico de Roque Barcia haciéndose pasar por él. También hace alusión al uceleberrimo Roque Barcias, Nicasio Camilo Jover en su obra: Las fragatas insurrectas y el bombardeo de Alicante, p. 69. Incluso Pérez Galdós en La Primera República, Alianza Editorial, Madrid, 1986, alude en varias ocasiones a este personaje a quien califica «mirifico» y «desatinado evangelista». En dos fragmentos de esta obra se observa la resonancia social de Barcia: «Cerca de mi, un sujeto leía en alta voz en ruedo de bebedores, el folleto de Roque Barcia El papado ante Jesucristo, escrito en conceptos bíblicos que eran la forma habitual de ese desatinado evangelista. Comentaban las gentes con risas o alabanzas las frases de latiguillo que eran la salsa del folleto (...). Como sabio da quince y raya a todos los tíos de las academias y ateneos de Madrid (....) yo he leido esas «Biblias» que escribe don Roque, y crea usted que con aquel fraseo tan pulido me quedo tonto y me subo al quinto cjelom, pp. 84 y 137.

${ }^{41} \mathrm{La}$ aversión a los jesuitas fue quizás la actitud anticlerical más ampliamente compartida en el Sexenio Democrático. Este rechazo social se manifestó claramente en las medidas religiosas tomadas por la mayor parte de las Juntas revolucionarias, algunas de las cuales fueron posteriormente recogidas por el Gobierno Provisional. Como indica Moliner Prada, Antonio Romero Ortiz «no dudó a los pocos días de hacerse cargo de su ministerio, el 12 de octubre de 1868, en suprimir la companía de Jesús e incautarse de sus propiedades y temporalidades. Inclusso se prohibió a los jesuitas el poder reunirse en comunidad, en contra del mismo principio de libertad de reunión y asociación pacifica proclamado por los revolucionarios y por el Gobiemo Provisionaly, en E. La PARRa López y M. SUÁrez CoRTNA (eds.), El anticlericalismo español contemporáneo, p. 108.

${ }_{42}$ Las abundantes referencias al jesuitismo aparecen en las pp. 538, 621, 635, 702, 933, 934 y 1018 del T.I. Del T.II en las pp. 453 y 556 de Insurrección Federal. La actitud moderada que quiere

Actas del I Congreso de Historia de la Iglesia y el Mundo Hispánico

Hispania Sacra, 52 (2000) 


\section{III.3. La visión de la Iglesia y el clero}

Las reflexiones en torno a cuestiones de carácter religioso, el papel de la Iglesia en la sociedad o descripciones de actitudes y comportamientos clericales ante los cambios suscitados por la revolución encuentran escasa representación en las obras de nuestros autores. Excepto en el caso de los jesuitas, que ya analizamos en el punto anterior, la comunidad eclesiástica queda totalmente a salvo de comentario alguno que pueda hacer pensar en alguna discrepancia por parte de los autores alicantinos.

La aséptica actitud con que Blas de Loma y Corradi describe la vida conventual constituye una prueba de ello. Sin atacar en ningún momento a las religiosas señala el anquilosamiento de este tipo de instituciones frente a la modernidad, aunque desde luego se guarda muy bien de hacer juicios de valor. Queda al lector considerar su propia actitud frente a la existencia de los conventos: obstáculos al avance de los tiempos o guardianes de la esencia religiosa frente a la modernización:

«La estructura de sus habitaciones y el conjunto de sus accesorios sorprende, porque revelan lo que realmente son, lo que en realidad es un convento, esto es, un día de otro siglo encerrado entre cuatro paredes y mantenido como una incrustación inmutable en medio de las cambiables corrientes de la sociedad moderna que se han ido sucediendo alrededor de ese petrificado recinto, sin modificar en nada la expresión de sus eterna fisonomía y de su inalterable sen ${ }^{43}$.

transmitir el autor se observa perfectamente en esta frase en las que alude al Carlismo, la Compañfa de Jesús y el republicanismo: «Dos ideas extremas se unen muchas veces para distintos fines. El petróleo de la Federal puede alumbrar la triunfal entrada de Don Carlos). Sin embargo en esta amalgama de conspiradores las simpatias por los valores que defiende el carlismo vencen sobre las que tiene el autor frente a la Intemacional: «Este cabecilla (carlista), cuyo nombre se ha hecho ya muy célebre en la guerra civil que por desgracia devora nuestra patria, era m hombre audaz, fanático por sus doctrinas, intolerantísimo en materias religiosas, pero entusiasta por el honor y cuyo pecho albergaba, bajo una ruda corteza los más generosos sentimientos», p. 335 T. I. Cfr. la actitud de Palacio Valdés hacía el Carlismo que Soledad MIRANDA califica de «benévola simpatía», pero también de distanciamiento. En op. cit., p. 210 Por otra parte la relación entre jesuitas y carlistas es puesta de manifiesto en varias ocasiones: «Don Juan, (cabecilla carlista) que con la protección de los jesuitas tenía relaciones en todas partes, porque a todas partes extiende su influencia la Companía de Jesís”, p. 453. La falta de escrúpulos de esta organización eclesiástica no impedia que prestase su apoyo a la insurrección cantonal. En la p. 556, T. II. este autor pone de manifiesto el protagonismo de los jesuitas en la rebelión cantonal.

${ }^{43}$ B. DE LOMA Y CORRADI, Entrada en España de la Reina M. Victoria, pp. 32-33. La ambigíedad de este autor puede hacer pensar en un cierto progresismo, sin embargo Rfos CARRATłLÁ afirma que puede encuadrársele perfectamente en una actitud conservadora, la cual es especialmente evidente en su obra poética, donde «nunca la religión se convierte en motivo lírico o creador que supere el tono dulzón de unos poemas de catequesis", en Románticos y provincianos, p. 158. Así, aunque en algunos pasajes de Entrada en España deja entrever cierta afinidad por el republicanismo, en otros se declara 
A pesar de que este texto pueda contener una crítica a la vida contemplativa practicada por algunas órdenes regulares, la nota dominante en los escritos analizados es el elogio hacia los miembros del clero. En Pastor de la Roca dichos elogios adoptan nombre concreto en la persona del canónigo Isbert a quien este autor califica como «genio infatigable y caritativo, modelo de sacerdotes ilustrados y virtuosos, al cual Alicante, nunca podrá pagar la gran deuda que con el mismo tiene contraída por razón de sus virtudes y su ministerios» ${ }^{44}$. Desconocemos qué motivos hacen del mencionado sacerdote valedor de atributos tan positivos. Sin embargo, si examinamos la prensa del momento podemos comprobar que el calificativo de (ilustrado» está vinculado al clero libera ${ }^{45}$.

Pero quienes reciben realmente elogios unánimes a favor de sus actuaciones son las monjas dedicadas a actividades caritativas o asistenciales. En Insurrección Federal, Llofriu y Sagrera, señala la actitud de estas mujeres en el bombardeo de Valencia. «Esos ángeles tutelares del pobre y del enfermo» actuaron eficientemente en una ciudad, amenazada por la muerte, el incendio y la desolación». Destaca don Eleuterio especialmente la figura de una shermana de la caridad que recoge el último suspiro de un desgraciado ${ }^{46}$. Asimismo Nicasio Camilo Jover se refiere al bombardeo de Alicante y a la «caridad dispuesta a restañar la sangre» de dos «heroicas señoras (...) alentadas por la Comunidad de religiosas, en cuyo convento se hallaban, (...) rogando a Dios el momento de ejercer su misión sublime» ${ }^{47}$.

ferviente monárquico e incluso llega a una especie de eclecticismo entre los dos regimenes. Al principio de la obra señala que cjamás he sido adorador de la monarquía, me desagrada por instinto. Más aún, habitando en estos rincones de la provincia, en donde se siente más que se piensay. En otro pasaje describe al alcalde de Alicante como "persona de corazón y republicano de buena fe» $Y$ finalmente termina por resolver sus posibles problemas de conciencia señalando que Amadeo I «no es ni más ni menos que un presidente de una República», pp. 5,84 y 85. Sobre la actitud favorable al clero femenino de clausura Cfr. E. LlOFRU Y SAGReRA, La mujer de Alicante, p. 45.

${ }^{44} \mathrm{El}$ texto corresponde a la descripción del oficio religioso que el canónigo Isbert celebró en el Monasterio de la Santa Faz con motivo de la visita de Amadeo I. En J. PASTOR DE LA ROCA, Viaje a Alicante de SS. MM. Amadeo Iy M. " Victoria en marzo de 1871 , pp. 27.28.

${ }^{45}$. Vid. las referencias que $E l$ Eco de Alicante del 14 y 15 de agosto hace a José García Mora como digno representante del uclero liberal e ilustradow. El mismo periódico alude en sus números de 4, 9, 21 y 30 de marzo, y 11 de julio de 1871 a La Armonía, publicación cuyos redactores eran «ilustrados ministros del altar, que comprenden cúan perfectamente se hermanan la libertad y el catolicismo».

${ }^{46}$ E. LLOFRIU y SAGRERA, Insurrección Federal, p. 969, T. I, y p. 141, T. II. En periódicos caracterizados por su anticlericatismo también destacan los elogios a estas mujeres. Tanto La República Española como La Revolucion sefialan sus constantes muestras de abnegación y desinterés personal ken los dificiles momentos por los que atravesaba la capital alicantina con la epidemia de fiebre amarillas (vid. números correspondientes a ambos periódicos de noviembre de 1870).

${ }^{47}$ N. C. Jover, Las fragatas insurrectas y el bombardeo de Alicante, p. 141. Cfr. E. LLofrJU Y SAGRERA, Insurreccción Federal, p. 986, T. I.

Actas del I Congreso de Historia de la lglesia y el Mundo Hispánico Hispania Sacra, $52(2000)$ 
Llofriu y Sagrera también caracteriza positivamente al clero a través del padre Ruiz, uno de los personajes de su obra Gloria, Dinero y Mujer:

«Era aquel sacerdote uno de esos tipos que honran al clero. De una virtud jamás desmentida, el cura era el consuelo de los afligidos, el socorro de los pobres, el mediador carifioso de toda reyerta. Si un matrimonio tenía en su casa desavenencias el buen sacerdote procuraba llevar la paz al hogar doméstico» ${ }^{48}$.

En unos tiempos tan agitados desde el punto de vista político los favoritismos de esta índole por parte de miembros del clero eran inevitables. En las obras analizadas aparecen dos alusiones claras en este sentido. La primera responde a un cura de Sax que expresa públicamente su entusiasmo monárquico ante el paso de Amadeo I por esa localidad en su viaje hacia Aranjuez ${ }^{49}$. La segunda apunta la excepcionalidad de curas liberales en el panorama políticoreligioso del momento:

«Los pasajeros miraban con extrañeza a aquellos hombres. Es internacionalista -decía el duefio de una fábrica, mirándolo con recelo. Lo he visto entre los grupos de las hueigas. -Dicen que perteneció a la Comunne-afiadía un sacerdote que por rara excepción era liberals ${ }^{50}$.

En los planteamientos sobre reforma social que surgieron durante el Sexenio el debate en torno a la cuestión religiosa adquirió una gran relevancia. Concretamente la libertad de cultos propició las más arduas discusiones en las Cortes Constituyentes que aprobaron esta medida secularizadora el 5 de mayo de 1869. En las obras analizadas no existe ninguna referencia a este tema si exceptuamos la obra de Nicasio Camilo Jover, Las amarguras de un rey ${ }^{51}$. Esta es una novela histórica, escrita antes de la mencionada promulgación. Su autor la presenta como un testimonio verídico ${ }^{52}$ sobre la vida en la corte de Alfonso $X$. Entre sus páginas pueden descubrirse algunas pinceladas de la ideología de

\footnotetext{
${ }^{48}$ E. Llofriu y SAGRERA, Gloria, Dinero y Mujer, Madrid, 1872, pp. 109-112.

49 J. PASTOR DE LA ROCA, Viaje de SS.MM..., p. 70.

so El comentario se refiere a Pedro Lefranc. En E. LLofrIU Y SAGRERA, Insurrección Federal, p. 600 , T. I.

51 N. C. Jover, Las amarguras de un rey, Imprenta de El Comercio, Alicante, 1868.

52 Juan Antonio Ŕos CARRATALA señala al respecto que en el prólogo uel autor no reivindica el mérito literario de la obra, sino el que esté redactada con estricta sujeción a la Historia y después de haber consultado escrupulosamente gran número de documentos», pero la «historiografia del alicantino es pobre y su obsesión se centra en enumerar todas las posibles traiciones y sublevaciones urdidas en la corte de Alfonso X", en Románticos y Provincianos, pp. 44-47.
}

Actas del I Congreso de Historia de la Iglesia y el Mundo Hispánico Hispania Sacra, 52 (2000) 
Jover. Concretamente su actitud favorable a la tolerancia de cultos es puesta de manifiesto en una discusión «de carácter intelectual y científico», en la que participan entre otros, teólogos castellanos y el propio rey:

\begin{abstract}
"Ya hacia muchas horas que la disputa continuaba vivamente sostenida por todos los concurrentes: más de una proposición poco ortodoxa se había emitido ya con escándalo de los teólogos castellanos, y mil pensamientos de progreso intelectual se formulaban en cada uno de los discursos pronunciados por tan doctos varones. El Rey, cuya tolerancia en materia religiosa no tenía límites, (...) no anatematizaba ninguna idea por atrevida que fuese, y por eso los hombres de todas las religiones podian emitir su parecer con libertad en aquel santuario de la sabjdurian ${ }^{53}$.
\end{abstract}

En el nuevo modelo social que intentaron implantar muchos revolucionarios la Iglesia no debia desaparecer sino reformarse. Eleuterio Llofriu en Insurrección Federal también recoge alguno de los frutos de éste debate que en ese momento ocupaba gran parte de los periódicos alicantinos. Sin hacer mención explícita al proceso revolucionario alude fugazmente al ideal de los liberales más avanzados sobre la vuelta a la Iglesia de los primeros siglos en la prevalecerían los supuestos valores de un cristianismo primitivo, frente al embrutecimiento de siglos posteriores ${ }^{54}$.

\title{
III.4. Valores y moral vigente
}

Para comprender la moral y los valores vigentes en la sociedad decimonónica han de considerarse dos cuestiones: la convivencia entre un catolicismo tradicional cuyos valores y pautas de comportamiento siguen ancladas en el Antiguo régimen, y la emergencia y progresiva consolidación de la modernidad, que se manifiesta en la economía, el pensamiento y en la política religiosa a través del racionalismo, el capitalismo y la secularización. La convivencia entre de dos mundos tan antagónicos se proyectó en una doble moral y en muchos casos en una disociación entre una religiosidad pública, socialmente exigida, y un posible «escepticismo interior». La caridad institucionalizada, el problema de la esclavitud, la pena de muerte y en general la eficacia del sistema penitenciario constituyen objeto de reflexión o por lo menos de mención por parte de algunos de los autores estudiados.

El problema insoluble de la pobreza había sido tradicionalmente paliado por la Iglesia a través de la institucionalización de la caridad y la limosna ${ }^{55}$. Por otra

53 N. C. JOVER, Las amarguras de un rey, p. 263.

54 E. LLOFRIU Y SAGRERA, Insurrección Federal, p. 205. 98-109.

35 J. L. ARANGUREN, Moral y Sociedad. Introducción a la moral social española del siglo XIX, pp.

Actas del I Congreso de Historia de la lglesia y el Mundo Hispánico

Hispania Sacra, 52 (2000) 
parte la burguesía tenía en la menesterosidad una oportunidad idónea para escenificar piadosos sentimientos ${ }^{56}$. Pastor de la Roca, en su crónica sobre el Viaje a Alicante de SS.MM. Amadeo I y $M^{a}$ de la Victoria, destaca alguna de las actuaciones que en este sentido llevaron a cabo los monarcas, autoridades civiles e Iglesia. Entre las medidas adoptadas se acordó «distribuir a mil pobres una ración de pan y una peseta a cada uno. Dar una comida extraordinaria a los acogidos en los establecimientos de Beneficencia y a los presos en la cárcel y (....) distribuir a las nodrizas de expósitos de toda la provincia un donativo equivalente a una mensualidad». Además en la sección titulada "Donativos», al final de la obra, detalla todas las donaciones hechas por los monarcas con motivo de su visita ${ }^{57}$.

La esclavitud es incompatible con los principios propugnados por el catolicismo y desde luego con planteamientos modernizadores o progresistas. Pero la España "esencialmente católica» del último tercio del siglo XIX seguía manteniéndola en algunos de sus territorios coloniales. Dos de los autores alicantinos analizados en el presente trabajo pusieron de manifiesto esta contradicción en sus escritos. En ellos se observa un rechazo ante esta práctica, que sin embargo reportaba pingües beneficios a quienes la practicaban, que en muchos casos se declaraban cristianos sinceros ${ }^{58}$.

En Llofriu y Sagrera la actitud ante la esclavitud aparece algo difusa. En su obra Insurrección Federal, adopta una posición clara ante este fenómeno al caracterizar a un supuesto traficante de esclavos como «ser ruin y despreciable que se dedicó al comercio de esclavos» ${ }^{59}$. En la obra teatral El insurrecto Cubano, fundamenta la igualdad interracial en el cristianismo. Así, cuando el malvado Juan afirma que «los negros son mala gente/y se debe sospechar», Martín y Manuel (padre e hijo en la obra) se apresuran a señalar que «no hay más que

56 Antonio San MARTtN publica El siglo del Can-Can, Imprenta de la Galería Literaria, Colegiata, Madrid, 1872, en el mismo tomo donde aparece Gloria, Dinero y Mujer, de LLOFRU Y SAGRERA. Aunque no es un autor alicantino, su descripción sobre un baile de beneficencia merece ser reseñada porque pone de manifiesto esa noción de escaparate público: «A pesar del mal tiempo y de ser más de las doce de la noche, infinidad de sefforas con el vestido recogido, ligeramente calzadas y con el cabello artísticamente peinado lleno de flores y lazos, cruzaban las calles inmediatas al teatro Jovellanos, despreciando los rigores de aquella tempestuosa noche. ¿A dónde iban? La respuesta es muy sencilla. Aquella noche habia un baile de beneficencia en el teatro Jovellanos (...). Los productos dei baile se destinan a los pobres, lo cual, aun cuando es muy laudable, hace pensar que en nuestros dias la caridad, si ha de dar aigún resultado, tiene que ser estimulada con el poderoso incentivo del placern, pp. 87-91.

57 J. PAstor DE LA ROCA, Viaje a Alicante de SS. MM..., pp. 9 y 104. Cfr. DE LOMA Y CORRAD], Entrada en España, p. 36.

58 Cfr. La Revolucion, del 22 del 12 de 1868, El Municipio del 29 del 12 de 1872 y La Tertulia del 28 del 12 de 1872 y 21 del 1 de 1873

59 E. LlOFRIU y SAgRera, Insurrección Federal, p. 124, T. I.

Actas del I Congreso de Historia de la Iglesia y el Mundo Hispánico

Hispania Sacra, 52 (2000) 
una raza como hubo un Dios en la cruz. Quien al pobre negro ofende, niega de Dios el poder que hermanos nos quiso hacen ${ }^{60}$. Sin embargo en Castigo del Cielo dicha igualdad no se acepta como un hecho. Se considera más una concesión a determinado «tipo de negros» con buena conducta que como un derecho:

«Si entre los negros existen hombres dóciles que reciben instrucción aprovechándose de ella y son serviciales, fieles, amigos carinosos y llegan a conquistarse una posición al amparo de las leyes, otros hay que repelen roda idea que tienda a esclarecer su inteligencia, y que no obedecen más que a los instintos ciegos de una naturaleza no modificada por las costumbres, por las leyes, ni aun por principios religiosos. Negros hay que son del tipo de la fidelidad, de la dulzura y que con gusto se sacrifican por el que les ha hecho un beneficion ${ }^{61}$.

En cambio Rafael Campos Vasallo expresó sin ninguna ambigüedad su repulsa ante esta cuestión en sus poemas «El Negrero» y «A la abolición de la esclavitud»:

«ßBasta de esclavitud, basta! ¡Concluya/ El dominio del hombre sobre el hombre/Enaltezcamos del señor el nombre, / Y gritemos, juntando nuestras manos; ¡Todos hijos de un Dios, todos hermanos! ${ }^{62}$.

La pena de muerte y la eficacia de las cárceles en la regeneración del individuo para la sociedad fueron también objeto de reflexión durante este período. Alejandro Harmsen mantuvo una posición clara al respecto al negar la efectividad social de ambos sistemas. En su poema «La pena de muerte», publicado también en prensa ${ }^{63}$, seffala la necesidad de erradicar esta condena y la posibilidad de enmienda del condenado. Asimismo fundamenta su posición en la idea Rousseauniana de que el individuo no es del todo responsable de unos actos, debidos en gran parte a la ignorancia ${ }^{64}$. Harmsen no acepta «esos presidios, foco inmundo de gangrena moral», e igualmente rechaza la pena de muerte porque el verdadero mal no está en que el delincuente viva sino en que «ignora el bien». La ciencia y «ese Dios de la dulzura que no quiere que muera el pecadory serán la cura de estos individuos. Según este autor si España logra abolir la pena de muerte se colocará a la cabeza respecto a «esas otras naciones de que

60 E. Llofru y SAGRera, El Insurrecto Cubano, pp. 10 y 33.

${ }^{61}$ E. Llofruu y SAGRERA, Castigo del Cielo, p. 54.

62 R. CaMpos Vasallo, "A la Abolición de la esclavitud》, en $M i$ Album, p. 21.

63 A. Harmsen Garcta, "La Pena de Muerten, El Eco de Alicante, 6 de marzo de 1869.

64 A. HaRMSEn Garcia, Ensayos literarios, Imprenta de la viuda de Juan J. Carratalá, Alicante, 1870, pp. 99-104. Cfr. E. JLLFRUU Y SAGRERA también se refiere a la responsabilidad de la sociedad en el mal comportamiento de algunos individuos, en Insurrección Federal, p. 28 T. I. Sin embargo estas ideas entran en franca contradicción con las expresadas por el mismo autor al referirse a las prostitutas. Vid. Nota 78 .

Actas del 1 Congreso de Historia de la Iglesia y el Mundo Hispánico Hispania Sacra, 52 (2000) 
eres hoy joh mengua escarnecida!, porque te miran pobre y abatida ${ }^{65}$. Llofriu y Sagrera seffala igualmente jcuánto ganaría la sociedad si en vez de tener que castigar acudiese a evitar el mal, a precaverlo atacándolo en su origen ${ }^{66}$.

\section{III.5. Religiosidad femenina}

En la sociedad que estamos analizando a través de sus escritos literarios la posición femenina estaba claramente definida a través de una especie de determinismo de carácter biológico a partir del cual la mujer estaria más cerca del mundo de los sentimientos y particularmente de la religión. El modelo de mujer vigente en el siglo XIX se caracterizaba por el desempeño de unos roles muy concretos, ceñidos casi exclusivamente al hogar ${ }^{67}$ por lo que era considerada como el elemento idóneo para la preservación de la religión en el seno familiar.

Llofriu y Sagrera en La mujer de Alicante hace especial hincapié en «el corazón de la mujer, entregado por completo a la creencia y al sentimiento religioson y sobre todo en esa faceta femenina relacionada con la educación de los hijos, esos «tiernos capullos (que) han recibido el benéfico rocío que (da) al alma la luz de la religión.». De manera que «si la mujer, con sus creencias, con su fe, con su amor a todo lo maravilloso y grande, no influyera en el corazón de sus hijos para perpetuar aquellas ceremonias y sostener el espíritu religioso, esas costumbres languidecerían hasta desaparecer por completo". Resulta por tanto lógico que la «adoración frenética» que siente la mujer por los símbolos más representativos de la religión sea inculcada «en el corazón de sus hijos» ${ }^{68}$.

${ }^{65}$ Ibidem, pp. 101 y 104 También Nicasio Camilo JOVER en Las amarguras de un rey rechaza la pena de muerte, considerándola un vestigio de épocas oscurantistas y bárbaras, p. 359.

${ }^{6}$ E. Llofriu y SAgrera, Gloria, Dinero y Mujer, p. 36, T. II. J. L. Aranguren, sefiala que el rechazo a la pena de muerte es un elemento característico en la mentalidad romántica, «El hombre romántico se rebela entre otras cosas contra el reo de muerte y el verdugo, como individuos sobre los cuales, arbitrariamente, la sociedad hace incidir toda la injusticia que ella misma produce y segrega y toda la repugnancia que oscuramente siente ante la pena de muerte». En "La crisis de reajuste de la antigua a Ja nueva existenciay en I. M. ZAVALA, Romanticismo y Realismo. Historia Crítica de la Literatura Española, Crítica, Barcelona, 1982, pp. 57-58.

67 "La sociedad española del siglo XIX consideraba a la mujer un ser vicario, decorativo y reducido al ambiente familiar, lo que no exigía más bagaje intelectual que la lectura, escritura, religión y moral, cálculo, costura y bordado y algo de música y canton en V. GARCiA DE LA CONCHA, op. cit., p. xxxv. Cfr. Galdós, Gloria, p. 26, donde la educación de la protagonista se ajusta a ese perfil.

${ }^{68}$ E. LlofRUU Y SAGRERA, La mujer de Alicante, pp. 49, 52 y 56 . Esta obra pretende trazar los caracteres más representativos de las mujeres en los distintos pueblos de la provincia. Se reduce a un texto en el que la mujer únicamente destaca por su abnegación social y su catolicidad. 
En esta misma obra la religión es un atributo más del elemento femenino, especialmente si se manifestaba a través de la caridad, una virtud a resaltar en la «mujer de elevada posición social» ${ }^{69}$ y sobre todo, si era una reina quien la ostentaba. En este sentido tres obras resaltan la religiosidad de la reina $\mathbf{M}^{2}$ Victoria en su visita a la capital alicantina. Bonifacio Carrasco de Campos alude a la religiosidad real en los siguientes términos: «De viva fe raudal inextingibles ${ }^{70}$. José Pastor de la Roca y Blas de Loma y Corradi ensalzan igualmente a la recién estrenada reina señalando su religiosidad verdadera frente a la inautenticidad de manifestaciones religiosas superficiales:

«La Reina por su parte permanece apoyada de codos, en un profundo y devoto recogimiento, el rostro cubierto con ambas manos, absorta y contemplativa, su actitud es sobremanera edificante, artísticamente sublime (...). Vedla ahí concentrada en si misma, entregada a su conciencia, puesta en relación con otra cosa inmaterial más grande, levantando el espiritu en doble éxtasis (...). Ese corazón tan piadoso, cuyo ascetismo culto, sólido sin ser fanático, merced a esa vasta instrucción que proverbialmente se la reconoce, constituye el mayor ornamento moral de la mujer, la cual sin religión no puede ser buena hija, buena madre, buena esposa, ni buena reina.s

Frente a la profusa descripción de los sentimientos religiosos de la reina se contrapone la religiosidad del rey de quien el mismo autor, en uno de los numerosos actos religiosos celebrados con motivo de su visita, se limita a señalar que «S.M. ora ante todo en la capilla y besa el crucifico que le presentan» ${ }^{71}$.

De las más alta esferas de la sociedad descendemos al pueblo llano. También en esta caso la religiosidad femenina constituye motivo de elogio para los autores alicantinos. Concretamente Juan Vila y Blanco en La Ermita del Santisimo Sacramento y de Nuestra Señora del Rosario en la Pedrera describe a la mujer que milagrosamente encontró un viril robado como «viuda, muy pobre y muy

${ }^{69}$ La religiosidad constituye uno de los adornos más significativos de las mujeres alicantinas: «Hijas de Aspe, Monovar, Elda y Novelda, cuyo dulce trato, cuya mirada expresiva y cuyas creencias religiosas son tan dignas de mencionarse» en ibidem, p. 57 . En las damas de la alta sociedad uel fraternal cariffo para los pobres ofrecía una oportunidad idónea para expresar sus piadosos sentimientos y un atributo destacable que se unía a «la sencilla elegancia, el amor a las artes, el distinguido trato", p. 41. La Tertulia, en su números del 24 y 28 de marzo de 1872 describe una comida benéfica en la que participan «elegantes y distinguidas damasn. Vid. J. L. ARANGUREN, Moral y Sociedad, p. 98.

${ }^{70}$ B. Carrasco de CAMpos, Oda a la Reina Doña Maria Victoria, Imprenta de T. Fortanet, Madrid, 187I, p. 14.

7) PASTOR DE LA ROCA, Viaje a Alicante...., pp. 30 y 55. Aunque más escueto en sus descripciones sobre estos actos BLAS DE LOMA Y CORRADi también diferencia claramente la actitud religiosa del Rey reducida a un mero formalismo, frente a la religiosidad sincera de la Reina. Este mismo autor caracteriza al monarca como "valiente, Rey generoso, Rey moral, Rey inteligente", mientras que la Reina es digna, «modelo de madres, de hijas y de esposas, una Reina religiosa, sin preocupación», en Entrada en España, pp. 27,48 y 81 .

Actas del I Congreso de Historia de la Iglesia y el Mundo Hispánico Hispania Sacra, 52 (2000) 
cristiana, que significa en el país ser adicta a la Iglesia (y) emplearse en las devociones religiosas» ${ }^{72}$.

La poesía es uno de los géneros literarios que mejor se presta para ensalzar la figura femenina. Desde el punto de vista religioso los poemas dedicados a la Virgen son el mejor exponente de ello. Rafael Campos Vasallo, Tomás Clavel y Bosch, o Alejandro Harmsen recogen en su obras un buen número de este tipo de poesías ${ }^{73}$.

Sin embargo alguno de estos autores también utilizaron la poesía para criticar defectos «típicamente femeninos» como la frivolidad o la beatería. En la moral de la época se consideraba que ambos elementos apartaban a la mujer del ideal socialmente establecido a través de sus funciones de madre y esposa, a las que se unía una religiosidad sincera. Rafael Campos Vasallo en su poema «La bañista» hace hincapié en la superficialidad de algunas mujeres y en su «Letrilla» ataca a las beatas:

«De una niña sesentona/ Que historias a miles hurda/Y de un suspiro me aturda/Mirándose yá jamona/ Que en todos abona/ Que es la vida carga leve, /Y que en su existencia breve/ Piensa solo en Dios, me pasma/ $Y$ antes que tal cataplasma/ Que satanás me lleves ${ }^{74}$.

La beatería o la superficialidad podían considerarse pequeñas faltas al lado de la depravación que caracterizaba a las mujeres que se atrevían a involucrarse en política y que desde ese plano se acercaban hacia posiciones claramente ateas. El papel de la mujer era tan incuestionable en la sociedad del último tercio del siglo XIX que hasta los sectores más progresistas de la misma criticaban cualquier alteración en ese sentido ${ }^{75}$. Asimismo la mujer, como principal introducto-

\footnotetext{
72 J. VILA Y BLANCO, La Ermita..., p. 56.

73 T. Clavel y Bosch, Poesías, Imprenta de Rafael Jordá, Alicante, 1873, p. 55-57. En las pp. 9, 84 y 89 este mismo autor dedica otros tantos poemas a la Virgen, además de una gran cantidad de versos religiosos centrados en la muerte de Cristo. Cfr. A. HARMSEN, «El Caminanten en Ensayos Literarios, p. 120. Cfr. R. CAMPOS VASALlo, «La noche en el Calvario», en Mi Álbum, pp. 7-9.

${ }^{74}$ R. CAMPOS VASALLo, op. vit., pp. 67, 68 y 96. Cfr. T. Clavel Y BosCH, «A una locaw, op. cit., p. 51. Cfr. J. Rico AMaT, El infierno con honra. Zarzuela bufo-político-social. Establecimiento tipografico de R. Vicente, Madrid, 1870 , p. 69 , sefiala que las mujeres son "caprichosas y volubles". Critica la beatería a través de un diálogo mantenido entre Satanás y una beata: «(Sat.) Levanta tú la cabeza. Bien se conoce que eres hipócrita. ¿Qué has sido en el mundo?/ (Be): Beata para servir a Dios y a V.M/(Sat): ¿Es decir, que eres a un tiempo de Dios y del Diablo? (...) ¿Qué has hecho para que te condenen? (Be): Rezar en público y murmutar en secreto (...). Enguerrar matrimonios y deshacer bodas (...). Fingir virtudes en la calle y luego en casa....(Sat): Lo adivino. Seffor director de hornos y calderas, que se la trate sin ninguna consideración. Esta es la peor gente que viene al infiernom. E. LLOFRU Y SAGRERA en Gloria, dinero y mujer, T. I., p. 91, aborda el tema de la educación femenina y la frivolidad.

75 J. PASTOR DE LA ROCA, en Viaje a Alicante, hace hincapié en los antecedentes politicos de las mujeres que trabajaban en fábrica de tabacos, «cuya exaltación de ideas ha ido tan lejos en esta época».
} 
ra de la religión y la moral en el cuerpo social, debía estar supuestamente más alejada de las ideas materialistas que ya dentro del mundo masculino se consideraban como una excentricidad. Soledad Miranda seffala al respecto que en la literatura del momento «muy rara vez nos son presentadas mujeres con sentimientos religiosos falaces o que hacen de éstos instrumentos y escabel para intereses personales». Así pues, la impiedad y el ateísmo «serán en todo momento patrimonio del hombre, cuya superación vendrá siempre por la vía femenina» ${ }^{76}$.

En contra de lo afirmado anteriormente en Insurreción Federal aparecen personajes femeninos que se encuentran en las antípodas del prototipo de mujer sumisa y religiosa. Con Lucrecia y Dorotea, Llofriu y Sagrera intenta ejemplificar los extremos del desorden revolucionario y las consecuencias del uso ilimitado que el pueblo hizo de las libertades. En el primer caso se trata de una italiana cuyo esposo era "partidario de una política de orden, inclinado al principio religioso hasta ser entusiasta defensor de Pío IX, y dispuesto a formar en las filas de los soldados del papa. Ella por el contrario, hija de un garibaldino acérrimo, y después más avanzado aún había oído las teorias de la libertad llevadas al extremo» e incluso en sus arrebatos anticlericales «llamaba al clero clerigalla». Esta mujer «de carácter provocativo, quería que prevaleciese su opinión en el matrimonio, que su marido abjurase de sus ideas y que se hiciese amigo de sus adversarios». Lucrecia llegó a asesinar a este hombre «de noble corazón» y de «sentimientos humanitarios» para compartir cama e ideas con el agitador internacionalista Pedro Lefranc. Su influencia sobre la descarriada Lucrecia, había propiciado que ésta llevase al «extremo aquellas teorías» y que no tuviese «más Dios que la Naturaleza, ni más religión que su instinto, ni más freno para su voluntad, que su capricho. El descreimiento, la decepción, el terrible desencanto eran el fruto de las doctrinas aprendidas por Lucrecia. Cuando había podido disponer de algunas horas de descanso se había dedicado a leer el Diccionario Enciclopédico de Voltaire, Las Ruinas de Palmira, y otras obras que leídas por inteligencias oscurecidas con la sombra de la despreocupación son un semillero de máximas que producen consecuencias terribles en la sociedad. Ellas llevan la desconfianza del espíritu, le hacen dudar de la amistad, del amor, de la religión, de todo». El descreimiento de Lucrecia la llevaba a negar a Dios considerándolo como un «Ser Supremo que cada pueblo adora a su modo, pero que no es más que una fuerza creadora... más hija de la Organización especial de las sociedades que espíritu increado ${ }^{77}$.

\footnotetext{
Vid el periódico republicano La Revolución del 2 de diciembre de 1869 donde J. Albeniz se refiere a esta cuestión seffalando que las mujeres deberían estar «en el seno de su familia, seriamente ocupadas en las faenas domésticasy.

${ }^{76}$ S. MIRANDA, op. cit., pp. 63-65.

$n$ Para resaltar a Lucrecia el autor contrapone a la infeliz Rosalía, que «por el contrario era del tipo opueston. Tenía su alma todos los rasgos de la bondad, basada en el principio religioso de la fe, en la idea de Dios». En Insurreción Federal, pp. 648, 758, 759 y 760, del T. I.
}

Actas del I Congreso de Historia de la Iglesia y el Mundo Hispánico Hispania Sacra, $52(2000)$ 
La «desenvuelta y descarada» Dorotea, representa en la obra una militancia más activa de los ideales que intentaban socavar el orden establecido. Su papel en la misma se desarrolla en el «Club de la Federación Universal», donde según el autor se exponían «las más peregrinas teorías sobre el destino de la mujer en la sociedad, teorías que si fuesen realizables, harían de la virgen, de la esposa y de la madre, tan solo una vil y miserable prostituta». Para Dorotea «el recato el pudor, la virtud, la modestia, eran esclavitud». Sus palabras lo demuestran:

"Yo tengo la seguridad de que la mujer no será libre mientras las religiones existan, y por eso en la actualidad nuestros golpes deben dirigirse, no solo contra los gobiernos centralistas, sino también contra los clérigos.»

A la tribuna de oradores de éste club de Cartagena también accedieron otros individuos que «tronaron con acento indignado contra el privilegio, contra la desigualdad de fortunas, contra la organización de la familia, contra el matrimonio, contra el sentimiento religioson. La ideología conservadora del autor queda al descubierto en estas manifestaciones, así como las ideas progresistas que llegaron a circular durante esos días en Cartagena, al igual que en otros tantos puntos de España. Llofriu consideraba un desatino «acusar al cristianismo de ser la causa principal de la esclavitud de la mujer» porque si la mujer «ocupa hoy en la sociedad un lugar digno y respetable, a nadie se debe más que al cristianismo' (...). Decían los apóstoles del porvenir, como se llaman los socialistas, que la mujer necesita emanciparse. Eso es un error, contestamos nosotros: la mujer está ya emancipada (...) su destino no será, porque no puede ser otro, que el que le designa las leyes de las sociedades cristianas. En sus «tres estados») naturales, «virgen, esposa y madre», está su verdadero destino "aunque la sociedad se desquicie a favor de atrevidas y absurdas reformas». Estas discusiones en torno al papel de la mujer en la sociedad encuentran su justificación en la historia. Llogriu y Sagrera señala que si la condición de la mujer en el paganismo se reducía a la de uesclava o prostituta», debe precisamente al cristianismo «los derechos de que hoy goza» ${ }^{78}$. Sin embargo todo tiene su medida; el espiritu ultramontano no debía llegar a los extremos de Orihuela, donde según este autor las mujeres vivían sumidas en el oscurantismo ${ }^{79}$.

${ }_{78}$ Ibidem, pp. 432-449. El Comencio en una serie de capítulos dedicados a la «Educación de la mujer» se manifiesta de igual modo al sefialar que «si el cristianismo es la religión de la humanidad, es muy particularmente la religión de la mujer. En el evangelio pues, encontrará ésta la única y verdadera ciencia que debe grabar en su almau (16 de mayo de 1868). Respecto a las prostitutas Don Eleuterio muestra una actitud de total rechazo como se observa en el siguiente párrafo: «Uno de los jóvenes habla de las prostitutas contemplándolas como victimas de las preocupaciones sociales, como una mártir, y no dijo una santa, porque rechazaba en absoluto todas las religiones», p. 432.

79 E. LlofrIU Y SAGRERA, La mujer de Alicante, Madrid, 1872-76, p. 56. Sobre el arraigo de las creencias religiosas en la "clerical Orihuela» Vid El Comercio del 3 de noviembre y 12 de diciembre de 1868, La Revolución del 23 de enero de 1869, y La Tertulia del 21 de enero de 1873. 
III.6. Las heterodoxias foráneas e institucionales frente a la ortodoxia que emana el pueblo español

El pueblo es considerado por la mayor parte de estos autores como la encarnación de todo lo bueno. Las creencias religiosas, la Iglesia, su ceremonias o las tradiciones forman parte de su razón de ser. En la misma línea que Alarcón estos elementos sustentan el argumento de muchas de las obras estudiadas en las que se tiende a identificar «todo lo positivo y lo bueno en la conducta del pueblo español y de sus componentes con un catolicismo militante». Sin embargo el «radicalismo exasperado» puede llegar a infiltrarse en las «desprevenidas masas $\rangle^{80}$, cuya natural ignorancia propicia que una minoría exaltada las desvíe hacia el camino del mal ${ }^{81}$. El Sexenio Democrático y especialmente los sucesos de 1873, mostraron al sector más conservador de la sociedad, del que a nuestro entender forman parte muchos de los autores analizados, la cara oscura de la libertad y sobre todo el peligro de contagio de ideas subversivas procedentes del extranjero. Este es un «año clave para entender las posiciones y los planteamientos más conservadores» ya que «muchos creyeron que los acontecimientos que marcaron este año podian amenazar la seguridad y la propiedad ${ }^{82}$ Esta cuestión se encuentra especialmente representada en Llofriu y Sagrera quien en su Insurreción Federal, vaticina que mientras el pueblo "esté sumido en las tinieblas de la ignorancia (...) será cada día convertido en instrumento de los ambiciosos». A pesar de que «esta es la tierra de los grandes hombres, de la honradez y de la nobleza, no debemos convertirla en país de monos que no saben más que imitar sin conocimiento de lo que hacen» ${ }^{83}$.

El gran baluarte frente a la ignorancia del pueblo es la educación ${ }^{84}$, pero el subdesarrollo en el que se encontraba esta faceta estatal podía ser compensada

\footnotetext{
${ }^{80}$ S. Miranda, op, cit., p. 152.

81 «Muchos hombres como el Cuco se ven entre las masas en los dfas de agitación popular (...), entre los grupos que en puntos determinados se forman para hablar de política, y allí puede oírseles discutir y perorar, exponiendo las ideas más raras, las doctrinas más absurdas que puedan imaginarsè. En E. LlOFRIU y SAGRera, Insurrección Federal, p. 297, T. I. R. CAMpos Vasallo en Mi Album, p. 96, incide en la demagogia politica.

82 A. MAYORDOMO, "Actitudes y Conductas sociales ante la educación popular en la sociedad valenciana en la segunda mitad del siglo XIX), en VV.AA., Clases populares, cultura y educación $\mathbf{p}$. 165.

${ }^{83}$ E. LLOFRIU Y SAGRERA, Insurrección Federal, pp. 16 y 33, T.I. En la p. 123, T. I, hace hincapié en la «falta de educación politica y la ignorancia de nuestro pueblow.

84 Vid. El «Manifiesto de la Junta Provincial de Valencia» de 1872: «En las Naciones más atrasadas cuando el poder legislativo reside en el pueblo, los más audaces suelen conmoverlo y entorpecer su civilizadora marcha, en los más instruidos (...) no es posible que unos pocos subleven la opinión públican, en ibidem, p. 178.
} 
con lo que hasta el momento se había mostrado como un eficaz instrumento de control social: la religión. Así pues para el pensamiento conservador la extensión de ideas subversivas foráneas que cuestionaban la idea de Dios y por tanto la religión constituía un verdadero peligro de desestabilidad social. En esta línea se expresa Eleuterio Llofriu quien señala que esos principios barrenan «el respeto a la autoridad y el acatamiento a la ley». Además «caen por su base todos los deberes y se elevan hasta el infinito los derechos» y la justicia se convierte «en un absurdo inventado por los hombres, sin leyes inmutables a que atenerse». La sociedad entera pasa a ser «una especie de contrato tácito, donde todo el mundo tiene derecho y se olvidaba el principio del deben?. Se extendería «la indisciplina en el ejército, las insurrecciones injustificadas, el desequilibrio de los poderes públicos» ${ }^{85}$.

Desde el punto de vista político el socialismo era para el pensamiento conservador una de las principales heterodoxias extranjeras que embrutecían la pureza y natural «candidez» del pueblo español. Juan Rico Amat lo considera como sinónimo de escaso amor al trabajo en su parodía sobre la revolución de septiembre ubicada en el infierno ${ }^{86}$. En Llofriu y Sagrera el socialismo y la Internacional adquieren un claro protagonismo hasta el punto de constituir el eje de su obra Insurrección Federal. En esta obra, ser extranjero y socialista son atributos negativos. Así, Pedro Lefranc, uno de los «genios del mal y del desorden» es francés, es decir, «un miserable especulador, uno de esos extranjeros que vienen a Espaffa dándose aires de hombres superiores y como propagandistas de las nuevas ideas o agentes de asociaciones que prometen hacer feliz al pueblo» ${ }^{87}$.

La defensa de la tradición frente a las novedades «extranjerizantes» cobra especial protagonismo en el caso de Francia. Este país sigue siendo para los adalides del conservadurismo la principal fuente de ideas destructoras que contribuye a la desespañolización. De ahí surgen, según este pensamiento, las fal-

\footnotetext{
85 Estas ideas son las que sustenta el agente de la Internacional Pedro Lefranc y su amante Lucrecia en E. Llofriu y SAgRERA, Insurrección Federal, pp.759-60. Cft. Pi Y MARGall, La Reacción y la Revolución, Estudio preliminar y notas críticas a cargo de Antoni Jutglar, Anthropos, Barcelona, 1982, pp. 165-166, donde su autor niega a la religión ese papel de freno social: «Si suprimis el cristianismo, se me pregunta por fin ¿qué freno dejáis para los pueblos?- ¿No comprenderéis pues nunca que el deber está en la raiz misma de la voluntad humana, que se nos impone independientemente de todo precepto exterior y toda idea?"

${ }^{86}$ J. Rico AMAT, El infierno con honra, p. 6. El autor, claramente opuesto a los principios que pretendió implantar la revolución, desarrolla un argumento en tono humorístico en el cual varios demonios insurtectos desean hacer estallar la Gloriosa en el infierno. Por su puesto todos los revolucionarios esparioles y en general todos aquellos que no cumplen los requisitos de la moral conservadora se encuentran cumpliendo condena en el reino de Satanás. Cfr. E. LLOFRIU Y SAGRERA y su opinión sobre la holgazanería de federales y socialistas, en Insurrección Federal, p. 297, T. I.

${ }^{87}$ E. LlofruU y Sagrera, Ibidem, p. 32, T. I.
} 
sas propuestas regeneradoras que justifican un rechazo contundente por parte de la sociedad para regresar a lo genuinamente español. En muchos autores y especialmente en Eleuterio Llofriu sigue subsistiendo la vieja idea de que los principios procedentes de la Revolución Francesa acechan en forma de conspiración, que actúa a través de sociedades y agentes secreto ${ }^{88}$ que recurren incluso a la agresión armada para apoderarse de nuestro país minando todos aquellos valores que supuestamente integran lo "genuinamente hispano" ${ }^{89}$. Existe un «verdadero pueblo español que pedía tranquilidad» frente a una falsa imagen de pueblo trastocada por las influencias exteriores que solo podía mimetizar unas ideas cuyo significado le era ajeno ${ }^{\% 0}$.

El Sexenio Democrático supuso un nuevo paso en el proceso de secularización iniciado a principios del siglo XIX. En este avance hacia la modernización lo que para muchos era considerado como tolerancia para otros, temerosos del desorden social, se convirtió en heterodoxia religiosa institucionalizada por los revolucionarios. Dicha institucionalización constituía una amenaza «por partida doble, en el plano religioso y en el plano político, ya que se la (veía) tendente a suplantar la hegemonía del grupo dominantes ${ }^{91}$. En este sentido el matrimonio civil era considerado por los sectores más conservadores como un ataque a la Iglesia, cuando en realidad su promulgación nunca se planteó de forma excluyente $^{92}$. La opinión de Llofriu y Sagrera ante éste avance secularizador se refleja en varios fragmentos de sus obras. En Insurrección Federal achaca el mal funcionamiento de un matrimonio en el que la mujer «recibe a gentes extrañas

\footnotetext{
88 «Los agentes de la Internacional trabajan con mayor ardor que nunca y preparan huelgas imponentes que acrecentasen el desorden y que hiciesen más profundo el terror $(\ldots)$. En Paris la Comunne quemaba los palacios y derribaba la columna Vendome y en España no ha puesto los ojos en los monumentos artísticos, sino en las fábricas y en nuestros fértiles campos (....) ¿Por qué los internacionalistas franceses no incendian fábricas en Lyon? ¿Por qué los alemanes no convierten en ceniza sus grandes establecimientos industriales? (es la Internacional) la que en nuestra opinión está representando el principal papel en los tristísimos sucesos que nos aniquilan y destrozan nuestra querida patrian, en $\mathrm{E}$. LlOFriU y SAGRERA, Ibidem, pp. 203, 205 y 21,5, T. I. Cfr. GaLdós, Gloria, donde el secretario del obispo Don Ángel Lantigua, se refiere a Francia para seffalar el clima de desestabilidad social en ese país: « Oh Francia, Francia, bien merecido lo tienes!. Oiga usía ilustrísima y formará idea de cómo acaba un país por abandonar las vías del catolicismon, p. 125 .

89 Vid J. HerRero, Los origenes del pensamiento reaccionario español, Edicusa, Madrid, 1973.

${ }^{90}$ E. LLOFRIU SAGRERA, Insurrección federal, pp. 201 y 442, T. I.

91 E. Cros, Literatura, ideología y sociedad, Gredos, Madrid, 1986, pp., 109-110.

92 El matrimonio civil no entorpecía la celebración del sacramento, que podia efectuarse libremente, aunque desligándolo de cualquier noción de obligatoriedad en el ámbito civil, al circunscribirse exclusivamente a la esfera de lo espiritual. Vid. V. CARCEL OrTí, Iglesia y Revolución, pp. 226-227, donde señala que esta medida de carácter secularizador se consideró como un triunfo para quienes «no buscaban un choque frontal con la Iglesia sino una renovación de la mentalidad y práctica en consonancia con las nuevas realidades socio-culturales de los paises europeos»
}

Actas del I Congreso de Historia de la Iglesia y el Mundo Hispánico Hispania Sacra, $52(2000)$ 
en ausencia de su marido» a que no estén unidos por el «sagrado vínculo» eclesiásticon. Esta mujer, que por su puesto el autor caracteriza como un mal ejemplo, tenía la desfachatez de pensar que «la perpetuidad del matrimonio cuando no existe la pasión que une a dos seres, es un absurdom. Don Eleuterio señala que el origen de estas ideas se encontraba en los clubes donde mujeres «entregadas a la política y fanatizadas» equiparaban el matrimonio con un contrato que podia «disolverse por la mutua voluntad de los contrayentes». Así pues, este escritor se congratula del fracaso de la insurrección cantonal, puesto que con su triunfo «se hubiesen resentido los intereses morales y los más dulces lazos de la humanidad» ya que entre los revolucionarios de Cartagena, «había quien pensaba en llevar la revolución hasta el seno de la familia aboliendo el matrimonio y la autoridad paterna, partiendo de la peregrina idea del amor libre y declarando a todos los niños hijos del Estado ${ }^{93}$.

Para Juan Rico y Amat el matrimonio civil también es objeto de ataque. En El Infierno con honra se refiere a la cuestión al describir, desde su óptica particular, la situación del país durante la revolución:

«Voy a contaros/ lo que alli hay/Hay muchas leyes, pocas mejoras,/pocos deberes, muchos derechos/malas palabras, pésimos hechos/poco dinero, mucho fusil/hay pocos sabios y muchos pobres/malas costumbres/y mal tabaco/pocos garbanzos y mucho caco/muchos casorios a lo civil (...). Serán la dicha /de los demonios/los matrimonios /a lo civil (...). Hay cada robo que tiembla el orbe/ cada herejía que mete miedo. (...). Su más preciosa conquista es el matrimonio civil, en virtud del cual puede uno casarse y descasarse cuantas veces quiera (...). Eso es lo que más me gusta de todo. Un casamiento diario. IViva el casamiento civil! $\$$.

\section{III.7. Los descreídos}

La mayor parte de las voces que durante la revolución pedían la renovación de la Iglesia tradicional, podían llegar constituir la crítica anticlerical y antieclesial más enconada pero no trascendieron esta posición para declarar una ausencia absoluta de creencias religiosas. El caso de Pi y Margall es uno de los más significativos del Sexenio. Sus argumentos constituyen un claro alegato

93 E. Llofriu Sagrera, Insurrección Federal, pp, 647 y 656, T. I, y p. 433, T. II. En la p. 440 de este tomo seflala igualmente las ventajas del matrimonio para la mujer. En Castigo del Cielo esta medida de carácter secularizador, es considerada, por uno de sus personajes, como un atentado contra las tradiciones marcadas por la Iglesia: cochenta afios tengo, soltera soy, pero a mi podian haber venido esos picarazos de hoy esos que ahora no se acuerdan de la Iglesia y se casan por lo civil», p. 26.

94 J. Rico AMAT, El Infierno con honra, pp. 16-19. El matrimonio civil es una de las reivindicaciones de los demonios revolucionarios Lesnas y Pateta., p. 43

Actas del I Congreso de Historia de la Iglesia y el Mundo Hispánico Hispania Sacra, 52 (2000) 
contra la existencia de Dios, sobre la que Don Francisco hace prevalecer la razón. Eleuterio Llofriu, en su Insurrección Federal, también recogió el eco social de este personaje desde una posición muy distante al ateísmo. De él seffala que actuaba «con esa calma fría del que todo lo somete a la razón y marcha impávido por el camino que cree ha de conducirle al fin que se propone». La distancia ideológica que separa al autor $\mathrm{y}$ al político no implica la descalificación de Llofriu sobre un hombre que a pesar de estas ideas contaba con el respeto social ${ }^{95}$.

La increencia en los personajes de Insurrección Federal es sinónimo de depravación y caracteriza a los artifices del mal. Así, el "genio del desorden», Pedro Lefranc, negaba la existencia de Dios, una «horrible blasfemia» que era «el complemento de las ideas de aquel hombre». Sin embargo, el autor no renuncia a conceder el destello de la duda a Lefranc «tan descrefdo, tan ateo, tan dispuesto a sacrificar todo lo bueno» pero que en algún momento «llegó a sentir algo de eso que se llama fe, de ese sentimiento que eleva el alma a regiones del infinito, esperando consuelo". Igualmente Juan Robledo, otro de los «malvados» de la obra, «era un descreído, pero a los bordes del sepulcro despertó su conciencia ${ }^{96}$.

Sin embargo más allá de la caracterización religiosa a título individual, Don Eleuterio buscaba resaltar la incidencia popular de las ideas materialistas y el peligro derivado de su difusión social:

"Aún cuando no tuvieran otro inconveniente, esas ideas tendrían el grave, el invencible desencanto que producen, de la amargura que llevan al espiritu. La idea de un Dios, de un premio en la otra vida, de un Ser infinito (...) es un poderoso móvil para el alma. Materializar ideas como la de Dios es agotar la fuente de las ilusiones, manchar la flor de las esperanzas más dulces. Negád a Dios, y habreis destruido los lazos más puros entre los hombre y habreís conseguido materializar los sentimientos más santos. (...). Las teorías que niegan a Dios tal como nos lo ensefian a comprender nuestros padres, influyen indirectamente en la familia, debilitan los vínculos sociales, y deja de ser la religión un freno para la voluntad y los malos instintos.»

Y señala respecto a quienes profesan estas ideas como:

«Inteligencias perturbadas por el descreimiento, por esa despreocupación exagerada que, como dijo un grande ingenio, un ilustre escritor, es la gran preocupación de nuestro siglo" ${ }^{97}$.

95 E. LLORRU SAGRERA, Insurrección Federal, p. 369, T. I. La prensa alicantina también aludió al ateismo militante de $\mathrm{Pi}$, públicamente expresado en las Cortes. Vid. La Revolución, 6 de mayo de 1869. En su obra La Reacción y la Revolución, Pi y Margall insiste en el triunfo de la razón sobre la fe, p. 144.

${ }^{96}$ E. Llofriu SAGRera, Insurrección Federal, pp. 598 y 768, T.I, y p. 211, T. II.

${ }_{97}$ Ibidem, p. 759, T. I, y p. 433, T. II. 
También desde la poesía Alejandro Harmsen, rechaza al ateísmo. Con una relación amorosa como telón de fondo el autor expresa en los siguientes términos su actitud ante el fenómeno:

«Detesto a esos incrédulos/Qué siempre escucho/Negar que haya virtudes/En este mundo;/Más cuando pienso/Que nunca han visto a Cármen $/$ Los compadezcon" ${ }^{98}$.

Por su parte Juan Vila y Blanco decide combatir activamente al ateísmo publicando su obra La Ermita del Santísimo Sacramento. En este bastión contra el materialismo el autor hace especial hincapié en «el celo no extinguido y la gratitud, todavia sentimiento vivaz en muchos excelentes corazones, (que) continúa ofreciéndonos preciosos rasgos de veneración y de amor a los objetos santos y nos consuelan en estos días de impiedad y ateísmo, manifestándonos que no se han apartado de Dios todos los hombres $)^{99}$.

98 A. HARMESEN GaRCia, Enscoyos Literarios, p. 56.

99 J. VILA Y BLANCO, La Ermita del Santisimo Sacramento, p. VI.

Actas del I Congreso de Historia de la Iglesia y el Mundo Hispánico Hispania Sacra, $52(2000)$ 